\title{
Desenvolvimento local e inovação em atividades tradicionais: $o$ arranjo produtivo local de turismo Lagoas e Mares do Sul, Alagoas, Brasil
}

Local development and innovation in traditional activities: the local productive arrangement of tourism Lagoas e Mares do Sul, Alagoas, Brazil

\section{Développement local et innovation des activités traditionnelles: l'arrangement productive local de tourisme Lagoas e Mares do Sul, Alagoas, Brésil}

\author{
Desarrollo local e innovación en actividades tradicionales: la aglomeración productiva local de \\ turismo Lagoas e Mares do Sul, Alagoas, Brasil \\ Maria Cecilia Junqueira Lustosa* \\ (cecilialustosa@gmail.com) \\ Francisco José Peixoto Rosário* \\ (chicorosario@gmail.com)
}

Recebido em 07/07/2015, revisado e aprovado em 18/09/2015; aceito em 15/10/2015

DOI: http:/ / dx.doi.org/10.20435/1518-70122016110

\begin{abstract}
Resumo: O objetivo é demonstrar que a inovação é possível em atividades tradicionais visando ao desenvolvimento local. Analisou-se o caso da culinária do arranjo produtivo local de turismo Lagoas e Mares do Sul por meio da revisão de literatura e entrevistas com os integrantes do arranjo. A promoção de um evento gastronômico levou a uma inovação importante nos serviços de alimentação. É possível realizar inovações em atividades com forte enraizamento, preservando suas características tradicionais.
\end{abstract}

Palavras-chave: Desenvolvimento local. Inovação. Atividades tradicionais.

Abstract: The goal is to show that innovation is possible in traditional activities aiming local development. It was analyzed the case study of the cooking in the local productive arrangement of tourism Lagoas e Mares do Sul by doing the revision of the literature and interviews with members of the arrangement. The promotion of a gastronomic event led to an important innovation in feeding services. It is possible to innovate in activities with strong roots, preserving its traditional characteristics.

Key words: Local development. Innovation. Traditional activities.

Résumé : L'objectif est de démontrer que l'innovation est possible dans les activités traditionnelles visant le développement local. On a analysé le cas de la production culinaire du système productif local de tourisme Lagoas e Mares do Sul à travers une révision de la littérature et des entretiens avec ses membres. La promotion d'un évènement gastronomique a débouché sur une innovation importante dans les services alimentaires. Il est donc possible d'opérer des innovations dans des activités ayant un fort enracinement local tout en préservant leurs caractéristiques traditionnelles.

Mots-clés : Développement local. Innovation. Activités traditionnelles.

Resumen: El objetivo es demostrar que la innovación es posible en actividades tradicionales buscando el desarrollo local. Se analizó el caso de la culinaria de la aglomeración productiva local de turismo Lagoas e Mares do Sul por medio de una revisión de literatura y de la realización de entrevistas con los integrantes de la aglomeración. La promoción de un evento gastronómico llevó a una innovación importante en los servicios de alimentación. Es posible realizar innovaciones en actividades con fuerte enraizamiento, preservando sus características tradicionales.

Palabras clave: Desarrollo local. Innovación. Actividades tradicionales.

\section{INTRODUÇÃO}

Seguindo a tendência mundial de reestruturação produtiva ocorrida na década de 1990, iniciam-se no Brasil políticas voltadas para o desenvolvimento local com foco nas micro e pequenas empresas (MPEs). Essas novas políticas contrastam com o processo de desenvolvimento brasileiro ocorrido até o final da década de 1970, focado na estrutura- ção do parque industrial, apoiado em grandes empreendimentos - também conhecido como processo de substituição de importações.

Na esteira desse novo conjunto de políticas voltadas ao desenvolvimento local, estão as políticas com base em arranjos produtivos locais (APLs), que se constituem numa ferramenta que promove uma visão sistêmica, capaz de mobilizar meios e instrumentos para o desenvolvimento. Este último é entendido

* Universidade Federal de Alagoas, Maceió, Alagoas, Brasil. 
como um processo de mudanças estruturais, gerando dinamismo econômico, sustentabilidade ambiental, e inserção e empoderamento social.

A partir do início da década de 2000, vários estados brasileiros implementaram políticas de APLs, com uma diversidade de usos do conceito e da forma de condução da política pública. Os resultados de tais políticas foram diversos, indo além da geração de emprego, da renda e do aumento da produção, gerando efeitos de difícil mensuração, mas importantes para o desenvolvimento local. Exemplo disso é a inovação em atividades tradicionais - especificamente na culinária tradicional - ocorrida no arranjo produtivo local (APL) de Turismo Lagoas e Mares do Sul, em Alagoas, Brasil.

Nesse contexto, este artigo tem por objetivo mostrar que a inovação é possível em atividades tradicionais para promoção do desenvolvimento local, analisando o caso acima citado. Assim, busca-se evidenciar que as mudanças para melhoria da qualidade de vida não estão atreladas somente ao aumento de renda, mas que elementos da herança cultural também podem ser vetores de desenvolvimento local.

A literatura neoschumpeteriana enfatiza a inovação tecnológica no setor industrial. Poucas publicações tratam da inovação em atividades tradicionais, mais especificamente na culinária tradicional. Alguns autores europeus tratam desse tema, uma vez que a unificação europeia impôs padrões de qualidade contrários às tradições de fabricação artesanal de alimentos em alguns países.

Este artigo tem por embasamento a literatura sobre APLs da RedeSist ${ }^{1}$, o levantamento bibliográfico sobre inovação em alimentos tradicionais e as pesquisas realizadas pelos autores sobre a política de arranjos produtivos locais em Alagoas. Algumas entrevistas abertas foram realizadas para melhor entendimento dos resultados do festival "Sabor das Lagoas", que promoveu a inovação na culinária tradicional do arranjo analisado.

$\mathrm{O}$ artigo está dividido em cinco seções, incluindo esta introdução. A seção 2 traça as

\footnotetext{
${ }^{1}$ Rede de Pesquisa em Sistemas e Arranjos Produtivos e Inovativos Locais (RedeSist) da Universidade Federal do Rio de Janeiro, Brasil (www.redesist.ie.ufrj.br).
}

linhas gerais do processo de inovação a partir de uma abordagem neoschumpeteriana, destacando os tipos de inovação e a inovação em atividades tradicionais. A seção 3 traz um enfoque teórico sobre políticas de arranjos produtivos locais e mostra como esta evoluiu em Alagoas. A seção 4 descreve o APL de Turismo Lagoas e Mares do Sul e analisa o festival "Sabor das Lagoas", considerado uma inovação em si e também um indutor de inovações na culinária tradicional. Na última seção, encontram-se as considerações finais do artigo.

\section{PROCESSO DE INOVAÇÃO}

A investigação sobre o processo de inovação de uma maneira não ortodoxa ${ }^{2}$ inicia com análise da mudança técnica, a partir da abordagem evolucionária, originária dos artigos seminais de Nelson e Winter $(1977,1982)$. Os autores transpõem conceitos da biologia evolucionária para a economia, uma vez que há processos e fenômenos que compartilham características comuns às duas ciências - inovação e seleção -, cabendo à biologia a primazia na formulação. Contribuições teóricas dos neoschumpeterianos foram incorporadas, iniciando com Freeman $(1974,1984)$, no sentido de resgatar as ideias de Josef Schumpeter.

Segundo Hall (1994), o processo de inovação corresponde a todas as atividades que geram mudanças tecnológicas e a interação dinâmica entre elas, que não precisam ser invenções primárias. Ao inovar, a empresa está buscando solução para determinado problema, que é resolvido dentro de um paradigma tecnológico, isto é, dentro de determinados padrões de soluções amplamente aceitos, baseados nos princípios das ciências naturais. Assim, uma vez estabelecido o paradigma tecnológico, as inovações tornam-se seletivas na capacidade de solucionar problemas, ao mesmo tempo em que encobrem outras soluções que estariam fora do paradigma

\footnotetext{
${ }^{2}$ Nelson e Winter (1982) definem a ortodoxia como a formalização moderna e a interpretação do pensamento econômico ocidental tradicional, que tem suas raízes em Adam Smith e David Ricardo, com desdobramentos em John Stuart Mill, Alfred Marshall e Leon Walras. Além do mais, a ortodoxia preocupa-se principalmente com o método de análise econômica e secundariamente com questões específicas.
} 
tecnológico - caracterizando uma "cegueira" do paradigma tecnológico predominante. As tecnologias são eleitas no processo seletivo, que, de acordo com as características predominantes do ambiente seletivo, escolhem determinadas tecnologias e não outras.

Entretanto, quando as dificuldades para achar soluções tornam-se crescentes, há um forte incentivo para a mudança de paradigma tecnológico, mas esta não é uma condição suficiente visto que, para se estabelecer um novo paradigma, é necessário que ocorram avanços no conhecimento básico, além de outros fatores institucionais e de mercado. Assim, o paradigma tecnológico dominante e o ambiente seletivo estabelecem o ritmo e a direção do progresso técnico, que pode até gerar uma mudança de paradigma, num processo lento e gradual.

Dentro do paradigma tecnológico vigente, é selecionada uma determinada tecnologia. Segundo B. Arthur (apud LÓPEZ, 1996), a tecnologia não é eleita por ser a mais eficiente, porém torna-se mais eficiente porque foi eleita, isto é, as tecnologias tornam-se mais atrativas quanto mais são utilizadas. Assim, a tecnologia possui interdependência temporal (path-dependent), ou seja, ela será resultado de trajetórias previamente definidas. Isso gera um efeito de lock-in, fazendo com que as empresas fiquem presas à tecnologia mais difundida e ao paradigma tecnológico vigente. Esses eventos têm grandes efeitos sobre a capacidade da empresa em achar soluções para problemas específicos, ou seja, sobre a capacidade de inovar da empresa.

Rosemberg (1976) aponta alguns fatores que poderiam induzir as inovações tecnológicas: problemas tecnológicos entre as atividades inter-relacionadas; escassez ou abundância de insumos; composição, mudanças e taxas de crescimento da demanda; mudanças no custo de produção e padrões de concorrência industrial. Mesmo sendo esses fatores de caráter predominantemente econômico, outros fatores não econômicos institucionais e sociais - têm grande influência no processo inovativo, pois estão diretamente relacionados com o ambiente seletivo.

Um importante debate sobre o processo de inovação está na sua mensuração, dada a necessidade de se obterem indicadores que reflitam as mudanças na natureza e no pano- rama evolutivo das inovações, permitindo elaborar instrumentos analíticos para pesquisadores e formuladores de políticas. A fim de preencher essa lacuna, a Organização para Cooperação e Desenvolvimento Econômico (OCDE) e o Gabinete Estatístico das Comunidades Europeias (Eurostat) produziram o Manual de Oslo, que em sua primeira versão, em 1972, considerava somente as inovações tecnológicas. A noção de inovação foi ampliada, e, na terceira versão do manual, em 2005, foi incluída a discussão de outros tipos de inovação - organizacional e de marketing -, ampliando ainda mais o escopo de análise do processo inovativo.

\subsection{Tipos de inovação}

De acordo com o Manual de Oslo (OCDE; UE/EUROSTAT, 2005), a inovação deve ser vista a partir da empresa individual. "O requisito mínimo para se definir uma inovação é que o produto, processo, método de marketing ou organizacional sejam novos (ou significativamente melhorados) para a empresa" (OCDE; UE/ EUROSTAT, 2005, cap. 3 , §148). A inovação pode ser inédita, desenvolvida pela própria empresa, ou copiada de outras que já tenham adotado tais inovações.

A literatura sobre inovação enfatiza as inovações tecnológicas - de produto ou processo -, porém há outros tipos: de marketing e organizacionais. A inovação de produto inclui tanto bens como serviços, sejam eles novos, com melhoramentos em suas funções ou no seu uso. Para fins de análise do estudo de caso, o foco é direcionado para a inovação de serviços.

As inovações de produtos no setor de serviços podem incluir melhoramentos importantes no que diz respeito a como elas são oferecidas (por exemplo, em termos de eficiência ou velocidade), à adição de novas funções ou características em serviços existentes, ou à introdução de serviços inteiramente novos. (OCDE; UE/EUROSTAT, 2005, p. 58).

A "[...] inovação de processo é a implementação de um método de produção ou distribuição novo ou significativamente melhorado. Incluem-se mudanças significativas em técnicas, equipamentos e/ou 
softwares" (OCDE; UE/EUROSTAT, 2005, p. 58). O objetivo desse tipo de inovação está relacionado à redução dos custos de produção ou distribuição, à melhoria da qualidade do produto e à distribuição de produtos novos ou significativamente melhores.

Quanto à inovação de marketing, ela é descrita como a "[...] implementação de um novo método de marketing com mudanças significativas na concepção do produto ou em sua embalagem, no posicionamento do produto, em sua promoção ou na fixação de preços" (OCDE; UE/EUROSTAT, 2005, p. 59). Assim, essas inovações relacionam-se com mudanças significativas no design do produto, abertura de novos canais de vendas, promoção de produtos - utilização de novos conceitos para promover produtos ou serviços, e novas estratégias de fixação de preços.

Finalmente, a "[...] inovação organizacional é a implementação de um novo método organizacional nas práticas de negócios da empresa, na organização do seu local de trabalho ou em suas relações externas" (OCDE; UE/EUROSTAT, 2010, 2005, p. 61). O objetivo é a melhoria do desempenho da empresa por meio da redução dos custos administrativos, de transação e de suprimentos; do estímulo à satisfação dos funcionários e da produtividade do trabalho; do acesso a ativos não transacionáveis; dos novos métodos para o estabelecimento de rotinas e procedimentos, como melhorias no compartilhamento da aprendizagem e do conhecimento; novas formas de organizar a relações com organizações públicas e privadas.

Apesar da tipologia de inovação, há casos de fronteira, em que uma inovação apresenta características que podem enquadrá-la em mais de um tipo descrito acima. O Manual de Oslo detalha as diretrizes para analisar e distinguir os diferentes tipos de inovação.

\subsection{Inovação em atividades tradicionais}

A inovação em atividades tradicionais, especialmente em alimentos, é alvo de estudos recentes na literatura especializada. Por um lado, existe certa incompatibilidade entre o conceito de inovação e a ideia de algo tradicional (INNOVATION..., 2010). Por outro, existe uma demanda crescente por produtos alimentícios tradicionais, sendo que a inovação assume uma importância crescente para melhorar a competitividade das empresas que produzem tais produtos (KÜHNE et al., 2007).

De acordo com Kühne et al. (2007), um alimento tradicional precisa ter uma receita autêntica, e/ou as matérias-primas de origem autêntica, e/ou um processo de produção autêntico. A gastronomia tradicional se enquadra nessa classificação e é considerada como um elemento de atração turística e de desenvolvimento local, tendo como suporte a herança cultural, que confere identidade ao território, integração e dinamismo (BESSIĖRE, 1998).

A importância da gastronomia tradicional para o desenvolvimento local está atrelada, em parte, à importância da experiência em nova cultura dada pelos turistas, descobrindo valores e raízes diferentes das suas, desfrutando seja do sabor da comida, seja do ambiente. Além do lado fisiológico, a gastronomia local também possui características sensoriais, sociais e simbólicas (BESSIÈRE, 1998). Assim, é um ativo intangível, que traz identidade para sua população, tornando-se um símbolo da localidade.

A herança cultural é uma marca de identidade, que distingue um grupo social de outro. É também um elemento subjetivo, pois está diretamente relacionada com a memória cultural coletiva, que preserva a cultura e a identidade social, por circunstâncias mais ou menos ritualizadas. Não obstante, existe a construção da herança cultural, que significa atualizar, adaptar e reinterpretar os elementos do passado de determinado grupo social, combinando conservação e inovação, estabilidade e dinamismo, reprodução e criação (BESSIÈRE, 1998).

Dessa forma, a inovação na gastronomia tradicional faz parte da herança cultural e de sua construção, colocando a inovação como um elemento dinâmico nesse processo. Além do mais, a inovação tem sido apontada como algo fundamental para obter vantagens competitivas. Ou seja, a inovação possui dupla relevância: na construção da herança cultural e na melhoria da competitividade local.

De acordo com Kühne et al. (2007), as empresas que ofertam comidas tradicionais não estão cientes da importância de inovarem e têm dificuldade de acesso a informações e 
parcerias que possam auxiliá-las nessa tarefa. Dessa forma, elas precisam de um ambiente que estimule a inovação e melhore a rede de relacionamentos entre elas e outras organizações. Esse arranjo institucional pode ser incentivado pelo governo.

A importância desse tipo de arranjo reside no fato de que o potencial inovativo das empresas está mais baseado num sistema local de inovação do que na empresa sozinha. A integração entre as empresas, seus fornecedores, seus clientes e outras organizações - governos, escolas, centros de treinamento, universidades, etc. - é que dará suporte ao processo inovativo, aumentando o fluxo de informações entre os agentes, possibilitando a difusão e a adoção das inovações (KÜHNE et al., 2007). Além do mais, oferece recursos externos às empresas, as quais, combinando com seus recursos internos, geram inovações de produto, de processo, organizacionais ou de marketing.

Concluindo, a valorização de atividades tradicionais, como a gastronomia resultante da herança cultural, traz benefícios econômicos, sociais e políticos. A atração de turistas que desejam ter a experiência de um paladar diferente gera emprego, renda e impostos, além do que torna a comunidade consciente de suas tradições, revelando sua identidade cultural, melhorando a interação entre os atores sociais. Assim, políticas públicas que valorizem as atividades tradicionais, e que, ao mesmo tempo, deem suporte a inovações para melhoria da competitividade, são amplamente necessárias.

\section{POLÍTICAS DE DESENVOLVIMENTO LOCAL A PARTIR DO ENFOQUE DE APLS}

\subsection{Políticas de APLs e MPEs: enfoque teórico}

A região como elemento constituinte e importante no processo de desenvolvimento é um tema recorrente na literatura econômica (SCOTT; STORPER, 2003). A discussão toma corpo no momento em que o atual processo de globalização se consolida no mundo a partir de fins dos anos 1980. Nesse momento, a localização passa a fazer parte das estratégias de crescimento e de redução de custos das empresas multinacionais. Tal processo termina por desenhar uma nova divisão internacional do trabalho como resultado dos processos de outsourcing conduzido por essas empresas.

Essa percepção é partilhada por vários autores quando se deparam com as dificuldades de trabalhar com os modelos de convergência do crescimento econômico. Fica a constatação de que é mais comum haver divergências nas taxas de crescimento econômico nos países do que algum tipo de convergência, como assinalado pelos esforços da teoria neoclássica do crescimento econômico (DOSI; FREEMAN; FABIANI, 1994).

A fonte fundamental das divergências de crescimento são as diversas formas com que vêm ocorrendo a urbanização e a industrialização dos países e regiões (SCOTT; STORPER, 2003), baseadas em condições diferenciadas de capacidades produtivas e capacitações tecnológicas (DOSI; FREEMAN; FABIANI, 1994).

Assim, a lógica "espaço e atividades produtivas" vem na discussão sobre o processo de desenvolvimento dos países e regiões, estas últimas especificamente da Europa, que elevam o território e suas características à condição de elemento determinante para a produtividade e a divisão eficiente do trabalho. Para dar conta dessa ampla agenda de pesquisa, a abordagem neoschumpeteriana trabalha com duas dimensões espaciais: a dimensão nacional, caracterizada pelos trabalhos em sistemas nacionais de inovação (LUNDVALL, 1988, FREEMAN, 1995); e a dimensão regional, analisada pela abordagem dos sistemas regionais de inovação (COOKE, 2001).

No Brasil, devido à grande heterogeneidade entre as regiões, suas capacidades e seus recursos produtivos, o tratamento analítico do aspecto regional do desenvolvimento dentro da corrente neoschumpeteriana está fundamentado nos estudos sobre arranjos produtivos locais, que é bem definida pelos trabalhos de Cassiolato e Lastres $(2001,2003)$ e Cassiolato, Lastres e Arroio (2005). Nesses trabalhos, ressaltam-se o papel da tecnologia, o conhecimento e aprendizado como elementos dinamizadores da localidade. O APL se estrutura como um arranjo institucional que permite ao território incorporar os novos 
conhecimentos e as novas tecnologias via aprendizado e vocação produtiva local.

$\mathrm{O}$ arranjo institucional permite, portanto, a estruturação de redes de empresas voltadas para o emprego do conhecimento desenvolvido em atividades inovativas, na difusão local de tecnologias, numa nova organização da produção e na construção de outros arranjos institucionais mais avançados, resultado de processos de coevolução (CASSIOLATO; LASTRES; ARROIO, 2005, CASSIOLATO; LASTRES, 2001).

O arranjo institucional, por sua vez, é composto por um conjunto de empresas e organizações que possuem capacitações distintas e que, de certa forma, conduzem o processo de geração e difusão de novos conhecimentos aplicados na organização da produção local. Ao ser sancionado pelo mercado, o modus operandi do conjunto de empresas, sua produção e a estrutura institucional garantem a competitividade do território.

O debate a respeito do desenvolvimento local passa, portanto, a ser também um debate a respeito da competitividade das empresas e regiões (MASKELL; MALBERG, 1999). O esforço então empreendido para desenvolver políticas de desenvolvimento passa pelo empenho de capacitação regional para a adequação e inclusão do sistema produtivo local nas cadeias produtivas nacionais, ou mesmo, internacionais (CASSIOLATO; LASTRES; ARROIO, 2005).

Como já foi dito, é comum às regiões apresentarem diferentes níveis de capacitações tecnológicas e produtivas que implicam diferentes intensidades de interações entre os agentes e robustez na estrutura institucional, resultando em importantes diferenças competitivas e, consequentemente, de desenvolvimento. Essa consideração é captada pelo conceito de APL aplicado pelos autores:

[...] arranjos produtivos locais são aglomerações territoriais de agentes econômicos, políticos e sociais - com foco em um conjunto específico de atividades econômicas - que apresentam vínculos mesmo que incipientes. Geralmente envolvem a participação e a interação de empresas - que podem ser desde produtoras de bens e serviços finais até fornecedoras de insumos e equipamentos, prestadoras de consultoria e serviços, comercializadoras, clientes, entre outros - e suas variadas formas de representação e associação. Incluem também diversas outras instituições públicas e privadas voltadas para: formação e capacitação de recursos humanos (como escolas técnicas e universidades); pesquisa, desenvolvimento e engenharia; política, promoção e financiamento. (CASSIOLATO; LASTRES, 2003).

Assim, as políticas para desenvolvimento regional baseadas em APL são, em primeira instância, políticas de competitividade territorial e, normativamente, vêm sendo apresentadas como uma das soluções para inclusão da produção local em cadeias produtivas mais abrangentes (CASSIOLATO; LASTRES; ARROIO, 2005).

As críticas apontadas para a organização da produção em APLs tocam particularmente os arranjos voltados para a exportação, pois Schmitz (2005) afirma que pequenas empresas encontram várias barreiras para a obtenção de conhecimento e inclusão produtiva nas cadeias produtivas internacionais. Dessa forma, a integração aos mercados nacional e regional representa um conjunto maior de oportunidades para as empresas dessas aglomerações produtivas e, portanto, apresenta um fato concreto para a elaboração e execução de políticas voltadas para o desenvolvimento regional. Essa política deve possibilitar o aumento da competitividade local via incorporação de modernas práticas de gestão, novos padrões produtivos e atividades inovativas nas empresas constituintes dos arranjos produtivos locais.

\subsection{Dinamizando regiões periféricas por meio de incentivos à produção, aprendi- zado e difusão de novas tecnologias: o Programa dos Arranjos Produtivos Locais de Alagoas (PAPL)}

A cultura empresarial em Alagoas está historicamente baseada no agronegócio para exportação de açúcar, em que as empresas eram passivas quanto ao esforço competitivo, pois o Estado e o mercado externo sempre ditavam a dinâmica do mercado. Os engenhos banguês, no século XIX, e, posteriormente, as usinas de açúcar são o que até 25 anos atrás melhor representava a trajetória do desenvolvimento alagoano. 
Tardiamente, o esforço para a diversificação da economia alagoana surge depois de uma década da saída do Estado do controle da produção e mercado do açúcar e álcool, ocorrido ainda em 1990. É em 2000, com a estruturação da Secretaria de Ciência, Tecnologia e Educação Superior (Sectes) de Alagoas, que o estado começa a pensar em alternativas e inserção competitiva para sua produção.

Como ainda reside a dificuldade de alterar uma estrutura produtiva e culturalmente arraigada em pouco mais de dez anos, a estratégia utilizada foi institucionalizar um programa de apoio a vocações produtivas existentes, mesmo que incipientes, para alavancar dois processos complementares: inserção da produção existente no mercado da capital e de estados vizinhos, e com isso melhorar a qualidade de vida das populações dessas localidades. Então, fica claro que esse programa pode representar o início de um processo de desenvolvimento.

$\mathrm{Na}$ trajetória da construção de institucionalidades voltadas para o desenvolvimento local, várias organizações alinharam-se a esse objetivo, ou mesmo foram criadas a fim de alcançá-lo. Por exemplo, com a instituição da Sectes, a Fundação de Amparo à Pesquisa do Estado de Alagoas (Fapeal) foi reestruturada em 2001, realizando concurso público para cobrir quadro de pessoal. Dentre as novas organizações voltadas para a geração de oportunidades para o desenvolvimento do estado, a criação da Incubadora de Empresas de Alagoas (Incubal) em 1999, ligada à Universidade Federal de Alagoas (Ufal), induziu à criação da Rede Alagoana de Incubadoras (RAI), a qual integra atualmente um conjunto de seis incubadoras espalhadas pelo estado.

O PAPL é um esforço para institucionalizar a governança dos APLs de Alagoas, sob a coordenação conjunta da Secretaria de Estado do Desenvolvimento Econômico e Turismo Sedetur- $\mathrm{AL}^{3}$ e do Serviço de Apoio às Micro e Pequenas Empresas em Alagoas (Sebrae-AL). O PAPL criou um novo ambiente econômico nos territórios e funciona como catalisador dos interesses e necessidades coletivas, mas que nem sempre, no estágio inicial de governança, fica claro para todos os atores.

\footnotetext{
3 Desde sua criação em 2004, o PAPL ficou a cargo de várias secretarias de Estado, que foram mudando suas atribuições e denominações - Seplan, Seplande e, atualmente, Sedetur.
}

Atualmente, são 18 arranjos fomentados, localizado em 83 dos 102 municípios alagoanos. Dez deles desenvolvem atividades ligadas à agropecuária ${ }^{4}$, quatro pertencem às indústrias de transformação e extração $0^{5} \mathrm{e}$ quatro, ao setor de serviços 6 .

OPAPLé o elemento aglutinador de várias organizações em torno dos arranjos, pois todos que atuam nos APLs estão em maior ou menor grau integrados ao programa. De fato, há uma gama de parceiros nos arranjos que se dizem colaboradores, mas não possuem atuação e compromisso com o programa. Outros estão diretamente ligados aos arranjos e atuam efetivamente, o que pode ser percebido pelas rodadas de negócios ${ }^{7}$ dos APLs. Nesse contexto, novas organizações foram criadas para atuar nos arranjos, como a Associação dos Empreendedores do Turismo do Litoral Sul de Alagoas (ASSERT Sul).

Enfim, a teia institucional vigente nos APLs de Alagoas foi e é fomentada por meio do esforço governamental e articulação de uma organização relevante, que é o Sebrae-AL. Por sua vez, essa instituição já apresenta uma organização interna resultante de evolução anterior em sua orientação de apoio às aglomerações de micro e pequenas empresas, em detrimento do apoio individual que fazia anteriormente a 2000, confirmando o modo colaborativo e de interdependência que marca a configuração e evolução de um sistema de inovação (EDQUIST, 2005).

\footnotetext{
${ }^{4}$ Apicultura no Litoral e Lagoas, Apicultura no Sertão, Fitoterápicos (plantas medicinais da agricultura familiar), Fruticultura no Agreste, Fruticultura no Vale do Mundaú, Horticultura no Agreste, Mandioca no Agreste, Ovinocaprinocultura no Sertão, Piscicultura no Delta do São Francisco, Rizicultura no Baixo São Francisco.

${ }^{5}$ Cerâmico Oleiro da Mesorregião Leste, Extração Artesanal de Granito na Zona da Mata, Móveis no Agreste e Móveis no Entorno de Maceió.

${ }^{6}$ Tecnologia de Informação em Maceió, Turismo Caminhos do São Francisco, Turismo na Costa dos Corais e Turismo Lagoas e Mares do Sul.

${ }^{7}$ A rodada de negócios é a segunda fase do ciclo anual de gestão de um APL, que consiste na identificação do financiador e executor das ações definidas na primeira fase, o planejamento. A terceira fase é a execução e coordenação (monitoramento) das ações (LUSTOSA et al., 2010).
} 


\section{FESTIVAL GASTRONÔMICO “SABOR DAS LAGOAS": INOVAÇÃO NA GASTRONOMIA TRADICIONAL}

O Arranjo Produtivo Local de Turismo Lagoas e Mares do Sul foi um dos arranjos fomentados pelo PAPL, iniciado em 2004, sob a denominação de APL de Turismo Região das Lagoas. Esse arranjo possuía um núcleo central, composto pelos municípios de Marechal Deodoro, Barra de São Miguel e o bairro do Pontal da Barra, no município de Maceió - com maior expressividade turística -, além dos municípios de Coqueiro Seco, Santa Luzia do Norte e Pilar. Em 2008, esse APL sofreu uma inflexão, quando foi ampliado e ganhou novo nome - APL de Turismo de Lagoas e Mares do Sul -, dada a inclusão de quatro novos municípios ${ }^{8}$, que fazem parte do litoral sul do estado.

Essa região destaca-se por apresentar vocação voltada para a diversidade cultural e gastronômica, além de seus atrativos naturais e culturais, que permitem que sejam desenvolvidas atividades como turismo cultural, ecoturismo, esportes náuticos e de lazer.

Por serem municípios litorâneos, em maioria, a pesca extrativista é a atividade mais tradicional, utilizando técnicas artesanais e absorvendo parte da população masculina economicamente ativa. Desta derivaram outras atividades, como o transporte de canoas e jangadas, a renda de filé ${ }^{9}$, o artesanato com motivos e matérias-primas do mar e a culinária utilizando os peixes e moluscos das lagoas e do mar. O enraizamento dessas atividades é grande, transformando o pescador e a beleza cênica em patrimônio cultural.

O arranjo não possui grande participação no PIB de Alagoas, sendo Maceió, a capital, responsável por quase $50 \%$ do produto estadual em 2007. O município de maior expressividade econômica do APLé Marechal Deodoro, com participação de cerca de $4 \%$ do PIB estadual nesse mesmo ano. A atividade econômica mais importante dessa região é a

\footnotetext{
${ }^{8}$ São eles: Roteiro, Jequiá da Praia, Coruripe e Feliz Deserto.

${ }^{9}$ A renda de filé é derivada da pesca, pois a base da renda assemelha-se a uma rede de pesca, sobre a qual a rendeira preenche os vazios e forma desenhos. É uma atividade cujo conhecimento tácito é passado de geração em geração.
}

agroindústria canavieira, na qual estão localizadas cinco unidades produtivas. Quanto às atividades primárias, há o predomínio da cocoicultura e da agricultura familiar para produção de subsistência. Como visto anteriormente, a pesca extrativa é de extrema relevância na absorção da mão de obra local, além de fazer parte da paisagem das lagoas. A aquicultura é também praticada, com o cultivo de ostras, porém em pequena escala.

A região do arranjo reflete a condição de pobreza de Alagoas, com os piores indicadores sociais do país. Os índices de desenvolvimento humano municipal (IDH-M) estão situados no último terço do ranking de IDH-M dos municípios brasileiros ${ }^{10}$ e os PIBs per capita são baixos.

É nesse território que atua a política que fomenta este APL de turismo. O arranjo está apoiado em seus atrativos turísticos naturais e culturais, associados aos serviços turísticos - comércio turístico, alimentação, meios de hospedagem, agenciamento e imobiliárias -, considerados as atividades do núcleo produtivo do arranjo.

O planejamento das ações do APL de Turismo Lagoas e Mares do Sul é feito anualmente, com a participação dos empresários que ofertam os serviços turísticos. Uma das ações de fomento ao arranjo foi a organização do festival gastronômico "Sabor das Lagoas", que surgiu da necessidade de promover a gastronomia tradicional da região. Especificamente, o festival visou:

- "Promover os pequenos negócios gastronômicos, reforçando a característica empreendedora e o potencial econômico do APL da Região das Lagoas e Mares do Sul;

- Ampliar o número de frequentadores dos bares e restaurantes da região/território, bem como suas receitas;

- Incentivar a participação dos empresários e empreendedores de bares e restaurantes e despertar o interesse comercial para a região;

- Dar visibilidade aos parceiros do APL da Região das Lagoas que acreditam na

\footnotetext{
${ }^{10}$ Na classificação nacional de melhores IDH-M, num total de 5509 municípios brasileiros, Maceió situa-se em 218o lugar; Marechal Deodoro, em 3786o e a Barra de São Miguel, em 3959o. O município de melhor IDH-M no Brasil é São Caetano do Sul, SP , com 0,919.
} 
capacidade empreendedora do território" (SEBRAE, s.d.).

Foram três edições do festival: em 2005 contou com 35 restaurantes; em 2006, com 45 participantes; e, em 2007, foram 36 estabelecimentos. Em cada ano, os restaurantes tiveram que elaborar um prato especial para o evento - inteiramente novo ou típico da região -, a partir da gastronomia tradicional e da criatividade dos chefes de cozinha, mesclando os frutos do mar e lagunar com outros ingredientes, como massas, pirão, arroz, derivados do leite, frutas, verduras, legumes etc. Em cada evento, foram cerca de cinco mil clientes que frequentaram os diversos participantes do evento.

Um importante resultado do festival, além dos já esperados, foi a identificação de pontos críticos na elaboração dos pratos de alguns restaurantes. Assim, foi implementado, em quatro restaurantes, o Programa Alimento Seguro (PAS) ${ }^{11}$, voltado para disseminação e apoio à implantação das Boas Práticas e do Sistema de Análise de Perigos e Pontos Críticos de Controle (APPCC) nas empresas de alimentos e de alimentação no Brasil.

Esse programa exige que as pequenas empresas adotem práticas de gestão de processos e produção que incentivam a adoção de melhorias na gestão do negócio como um todo. De forma indireta, permite maior capacitação tecnológica e competitividade para as pequenas empresas que conseguem seguir as recomendações do programa. As práticas exitosas no PAS em algumas empresas do APL se tornam exemplos importantes para que as demais também adotem esses padrões de produção.

Três restaurantes implantaram o PAS para terem condições de participar do festival. Outro estabelecimento, no entanto, já o havia implantado antes mesmo da realização evento. A importância do programa é maior para aqueles que não tinham anteriormente experiência no ramo de alimentação. Em geral, foram realizadas mudanças na armazenagem dos produtos - técnicas de congelamento - e melhorias na manipulação dos alimentos uniformes apropriados, higiene e limpeza dos

\footnotetext{
${ }^{11}$ OSenac participa da coordenação do PAS desde 2001, junto com outras instituições do Sistema S (Sesc, Senai, Sesi e Sebrae) (http:/ / www.senac.br/pas/index.html).
}

alimentos e dos locais de trabalho, inclusive a lavagem da caixa d'água. O treinamento foi dado para os funcionários e para os donos dos estabelecimentos, capacitando-os a seguir o manual de boas práticas. Houve mudanças na organização da empresa, pois os funcionários passaram a usar equipamentos de proteção individual e sentiram-se motivados em aprender, colocando em prática novos conhecimentos tanto no trabalho quanto na vida pessoal.

A implantação do PAS melhorou a qualidade dos pratos ofertados, levando o cliente a ficar mais satisfeito e trazendo novos clientes. O público tornou-se mais exigente, pois alguns fizeram questão de visitar a cozinha para ver se o restaurante trabalhava com qualidade na elaboração do cardápio ofertado. Além do mais, houve uma maior proximidade dos donos dos restaurantes, que passaram a ter melhor articulação entre eles e a dar maior importância à adoção de um padrão superior de qualidade, levando a região a ser reconhecida por ter bons estabelecimentos, seja pela qualidade, seja pelo sabor da comida.

A melhoria da competitividade foi reconhecida por todos os estabelecimentos entrevistados. Percebe-se, portanto, três de processos de inovação distintos induzidos pela política pública de APLs. O primeiro trata da realização do festival gastronômico "Sabor das Lagoas", uma inovação de marketing para os restaurantes, que se tornaram mais conhecidos dos turistas e visitantes, resultado da indução da própria política de fomento a APL. O segundo ocorreu nos restaurantes que elaboraram receitas inteiramente novas e exclusivas para o festival, pois este foi uma motivação para tal inovação de produto. Algumas receitas passaram a fazer parte do cardápio regular dos restaurantes, dada a ampla aceitação do público. O terceiro processo de inovação identificado deu-se nos estabelecimentos que adotaram o PAS, que levaram inicialmente a uma inovação de processo e, subsequentemente, a uma inovação organizacional.

\section{CONSIDERAÇÕES FINAIS}

O estado de Alagoas é um dos mais pobres do Brasil, e sua economia está apoiada na 
secular agroindústria açucareira. As diversas crises pelas quais passou esse setor e a necessidade de diversificação produtiva do estado levaram a um esforço para sua reestruturação produtiva, no final da década de 1990, dando início à atual configuração institucional para a implementação da política de desenvolvimento estadual baseada em arranjos produtivos locais - o PAPL. Essa política, que tem por base a geração de conhecimento, o aprendizado local e a inovação, apresenta como principal vantagem a estruturação da governança em regiões periféricas e subdesenvolvidas por meio do fomento aos APLs.

Um dos arranjos apoiados pelo PAPL foi o APL de Turismo de Lagoas e Mares do Sul, situado numa região costeira, ao sul da capital do estado. Um dos seus atrativos turísticos é a gastronomia local, elaborada à base de frutos do mar e das lagoas, mesclada com outros insumos locais. A questão que se coloca é a possibilidade de inovação em atividades tradicionais, de forma a não perder suas características originais e, ao mesmo tempo, melhorar a competitividade dos restaurantes, atraindo mais turistas.

A experiência de uma ação para o desenvolvimento local, o festival gastronômico "Sabor das Lagoas", comprovou que é possível ter inovação em atividades tradicionais. Nesse caso específico, houve três processos de inovação distintos induzidos pela política pública de fomento. O primeiro, a realização do festival foi uma inovação de marketing para os restaurantes, que se tornaram mais conhecidos dos turistas e visitantes. O segundo ocorreu nos restaurantes que elaboraram receitas inteiramente novas e exclusivas para o festival, incentivando uma inovação de produto. O terceiro foi a adoção do Programa de Alimento Seguro em alguns estabelecimentos, gerando inicialmente uma inovação de processo - higienização, manipulação e armazenagem dos alimentos - e, consequentemente, uma inovação organizacional - uso de equipamentos de proteção individual, observação de normas do manual de boas práticas alimentares.

Dessa forma, as inovações induzidas pela política pública apresentaram um duplo dividendo: a construção da herança cultural, levando ao reforço de identidade local, e a melhoria da competitividade dos restauran- tes, por meio da adoção de diferentes tipos de inovação. Isso foi possível devido à criação de um ambiente institucional capaz de dar suporte às empresas para desenvolverem suas capacidades inovativas, mostrando que a inovação em atividades tradicionais é possível e constitui-se num importante vetor de desenvolvimento local.

\section{REFERÊNCIAS}

BESSIÈRE, J. Local development and heritage: traditional food and cuisine as tourist attractions in rural areas. Sociologia Ruralis, v. 38, n. 1, p. 21-34, 1998.

CASSIOLATO, J. E.; LASTRES, H. M. M. Arranjos e sistemas produtivos locais na indústria brasileira. Revista de Economia Contemporânea, Rio de Janeiro, v. 5, ed. especial, 2001.

. O foco em arranjos produtivos e inovativos locais de micro e pequenas empresas. In: LASTRES, H. M. M.; CASSIOLATO, J. E.; MACIEL, M. L. (Org.). Pequena empresa: cooperação e desenvolvimento local. Rio de Janeiro: Relume Dumará, 2003.

COOKE, P. Regional innovation systems, clusters, and the knowledge economy. Industrial and Corporate Change, v. 10, n. 4, p. 945-974, 2001.

DOSI, G., FREEMAN, C., FABIANI, S. The Process of economic development: introducing some stylized facts and theories on technologies, firms and institutions. Industrial and Corporate Change, v. 3, n. 1, p. 1-45, 1994.

EDQUIST, C. Systems of Innovations. In: FAGERBERG, Jan; MOWERY, David C.; NELSON, Richard R. The Oxford handbook of innovation. Oxford: Oxford University Press, 2005.

FREEMAN, C. The economics of industrial innovation. 1. ed. Londres: Penguin Books, 1974.

. Long waves in the world economy. Londres: Frances Printer, 1984.

The National System of Innovation in historical perspective. Cambridge Journal of Economics, n. 19, 1995.

HALL, P. Innovation, economics and evolution: theoretical perspectives on changing technology in economic systems. New York: Harvester Wheatsheaf, 1994.

INNOVATION in traditional foods could harm their image. The Meat Site, 22 mar. 2010. Disponível em: <http:/ / www.themeatsite.com/articles/888/innovation-in-traditional-foods-could-harm-their-image>. Acesso em: 23 mai. 2011.

KÜHNE, B. et al. Barriers and drivers of innovation in traditional food networks. In: INTERNATIONAL EUROPEAN FORUM ON INNOVATION AND SYSTEM DYNAMICS IN FOOD NETWORKS, 1., 15-17 fev., 2007, Innsbruck-Igls, Austria: Universität Bonn-ILB Austria, 2007.

LASTRES, H. M. M.; CASSIOLATO, J. E.; ARROIO, A. (Ed.). Conhecimento, sistemas de inovação e desenvolvimento. Rio de Janeiro: UFRJ/Contraponto, 2005. 
LÓPEZ, A. Competitividad, innovacion y desarrollo sustentable: una discusión conceptual. DT 22, Buenos Aires: CENIT, 1996.

LUNDVALL, B.. Innovation as an interactive process: from user-producer interaction to the national system of innovation. In: DOSI, G.; FREEMAN, C.; NELSON, R.; SILVERBERG, G.; SOETE, L. (Ed.). Technical change and economic theory. Londres: Pinter, 1988. p. 349-369.

LUSTOSA, M. C. J. et al. Caracterização, análise e sugestões para adensamento das políticas de apoio a APLs implementadas nos estados - Alagoas. Projeto de pesquisa (BNDES/FUNPEC) - Análise do mapeamento e das políticas para arranjos produtivos locais no Norte, Nordeste e Mato Grosso e dos impactos dos grandes projetos federais no Nordeste. Nota Técnica 05/AL, Maceió/AL, 2010. Disponível em: <http:/ /www.politicaapls.redesist.ie.ufrj.br/documentos/docnorte>. Acesso em: 10 maio 2011.

MASKELL, P.; MALMBERG, A. The competitiveness of firms and regions: 'Ubiquitification' and the Importance of Localized Learning. European Urban and Regional Studies, v. 6, n. 1, p. 9-25, 1999.
NELSON, R.; WINTER, S. In search of a usefull theory of innovations. Research Policy, v. 6, n. 1, 1977.

. An evolutionary theory of economic change. Harvard: Harvard Un. Press., 1982.

OCDE; UE/EUROSTAT. Manual de Oslo: diretrizes para a coleta e interpretação de dados sobre inovação. 3. ed. 2005. Brasília: OCDE/Eurostat/FINEP. Disponível em: $<$ http://www.finep.gov.br/images/apoio-e-financiamento/manualoslo.pdf>. Acesso em: 10 abr. 2010.

ROSENBERG, N. Perspectives on technology. Cambridge, UK: Cambridge University Press, 1976.

SCOTT, A. J.; STORPER, M. Regions, globalization, development. Regional Studies, v. 37, p. 579-593, 2003.

SCHMITZ, H. Aglomerações produtivas locais e cadeias de valor: como a organização das relações entre empresas influencia o aprimoramento produtivo. In: LASTRES, H. M. M.; CASSIOLATO, J. E.; ARROIO, A. (Ed.). Conhecimento, sistemas de inovação e desenvolvimento. Rio de Janeiro: UFRJ/Contraponto, 2005.

SERVIÇO BRASILEIRO DE APOIO ÀS MICRO E PEQUENAS EMPRESAS - SEBRAE-AL. $4^{\circ}$ Festival Sabor das Lagoas. Maceió: Sebrae-AL, [s.d.]. 12 slides, color. 